\title{
3. \\ El contrato de seguro, el interés asegurable como uno de sus elementos esenciales y su relación con la entrega, la transmisión del riesgo y la transferencia de la propiedad
}

\subsection{INTERÉS ASEGURABLE COMO ELEMENTO DEL CONTRATO DE SEGURO}

El riesgo de pérdida de las mercancías, el interés asegurable sobre las mismas como elementos esenciales del contrato de seguro, la compraventa internacional de mercaderías y los INCOTERMS son figuras e instituciones jurídicas que no pueden mirarse, ni aislada ni parcialmente, so pena de incurrir en incoherencias sistemáticas que lleven a la toma errada de decisiones prácticas o a la adopción no acertada de posturas doctrinales. Si bien los INCOTERMS están diseñados para aplicarse a la compraventa, la utilización de algunos de ellos influye o trae consecuencias -casi que causales- para otros contratos, como son el de trasporte, seguro y financiación (Oviedo Albán \& Candelario Macías, 2009).

El interés asegurable como elemento esencial en el contrato de seguro, sin el cual no puede hablarse de existencia de contrato como tal, muchísimo menos de cobertura, falla cuando quien funge como asegurado en el contrato no ostenta una relación jurídico-económica con la mercancía, dado que la entrega y la transmisión de los riesgos se dio extemporáneamente al de la vigencia de la póliza.

A este respecto se pronuncia Perales Viscasillas (2002): 
La transmisión del riesgo envuelve una cuestión sencilla que, sin embargo, resulta muy difícil de responder: ¿quién se hace responsable cuando las mercancías se pierden o deterioran? La respuesta bajo la Convención de Viena es que la pérdida la soporta el comprador cuando los daños o la pérdida de las mercancías se producen una vez que el riesgo se le ha transmitido, a menos que se deba a un acto u omisión del vendedor (art. 66 CNUCCIM). La pérdida es económica, ya que las mercancías se pierden, pero la parte que soporta el riesgo no sólo las pierde sino que además ha de pagar el precio de las mismas (aunque las reciba deterioradas o nunca las reciba) o habrá de entregar las mercancías por segunda vez, recibiendo únicamente una contraprestación equivalente a una de ellas. Estas consecuencias se ven en gran medida mitigadas por la circunstancia de que las partes contratarán seguros cubriendo contingencias que den lugar a la pérdida o al deterioro de las mercancías, lo cual no evita que alguien tenga que pagar esos seguros, ni que la parte que asume el riesgo tenga la carga de tener que reclamar al asegurador.

Sin que se haga mención a la propiedad, sí parece estar al menos claro que tiene interés asegurable quien soporta el riesgo por pérdida o daño de las mercancías, y, a contrario sensu, faltará dicho interés y por ende el contrato de seguro (el que será nulo o inexistente dependiendo del sistema de sanción adoptado internamente) en quien no lo soporta, pese a que su patrimonio se puede ver seriamente afectado con la pérdida de la mercancía, pues en todo caso, le implicará un litigio en contra de quien, ostentando el riesgo, no accede a la reposición de la mercancía, la devolución del precio y/o el pago de los perjuicios.

Resultando irrelevante que lo estableciesen, las propias reglas de la CCI que tienen como obligación del vendedor proveer un seguro para las mercancías (CIF-CIP) se ocupan de extender la obligación hasta garantizar que el seguro pueda reclamarse directamente por el comprador o cualquier otra persona que tenga un interés asegurable sobre estas. Al respecto, las reglas A3 de los términos CIP y CIF establecen: "A3: El seguro deberá contratarse con aseguradores o con una compañía de seguros de buena reputación y dar derecho al comprador, o a cualquier otra persona que tenga un interés asegurable sobre la mercancía, a reclamar directamente al asegurador" (Cámara de Comercio Internacional, 2010, p. 52).

Tal como se viene de analizar, en la compraventa internacional de mercaderías, el riesgo por la pérdida o deterioro de las mismas se transmite con su entrega, sin perjuicio de lo que estipulen libremente las partes, pero en cada uno de los eventos, y en caso de que el riesgo por dicha pérdida esté asegurado, se deberá preguntar por quién debe asegurarlas y quién está legitimado para pedir la reclamación contra el asegurador (Oviedo Albán \& Candelario Macías, 2009). 
El contrato de seguro, entendido como aquel en el que una persona natural o jurídica traslada un determinado y permitido riesgo a otra persona jurídica autorizada para asumirlo a cambio de una contraprestación denominada prima y mediando la presencia de un interés asegurable en cabeza de quien traslada ese riesgo, se relaciona estrecha y necesariamente con la figura del contrato de compraventa internacional no solo en cuanto se constituye en un importante instrumento de protección y seguridad en las relaciones mercantiles internacionales, sino, además, porque el costo del seguro se encuentra estrechamente ligado con el valor en aduanas de las mercancías al momento de la importación, tanto así que, aun en caso de no contratarse seguro alguno en una determinada importación, es necesario calcular el costo estimado de la póliza para efectos simplemente aduaneros (valor en aduanas) ${ }^{1}$.

Dentro de las múltiples clasificaciones a que da lugar todo el régimen de seguros, y atendiendo a una pertinente delimitación teórica, tenemos que el estudio y regulación del seguro se circunscribe a dos grandes ramas como son las que corresponden a

1 En el marco del acuerdo relativo a la aplicación del artículo VII del Acuerdo General sobre Aranceles Aduaneros y Comercio de 1994 (Acuerdo de valor del GATT de 1994) el artículo 6º de la decisión 571 de la Comisión de la Comunidad Andina de Naciones, señala: Artículo 6.- Elementos a incluir en el valor en aduana: Todos los elementos descritos en el numeral 2 del artículo 8 del Acuerdo sobre Valoración de la OMC, referidos a los gastos de transporte de las mercancías importadas y gastos conexos al transporte de dichas mercancías hasta el puerto o lugar de importación, los gastos de carga, descarga y manipulación ocasionados por el transporte de las mercancías importadas hasta el puerto o lugar de importación y el costo del seguro, formarán parte del valor en aduana.

A su vez, el artículo 8 de la Resolución 846 de la Comunidad Andina de Naciones (Reglamento Comunitario de la Decisión 571 - Valor en Aduana de las Mercancías Importadas), al reglamentar lo inherente al método del valor de transacción, señala:

\section{Artículo 8. Precio realmente pagado o por pagar.}

1. De acuerdo con lo expresado en el párrafo 2 del artículo 4 anterior, la base fundamental sobre la cual descansa el método del Valor de Transacción de las mercancías importadas, es el precio realmente pagado o por pagar por estas mercancías como condición inherente a su venta.

2. El precio realmente pagado o por pagar es el precio de las mercancías importadas y constituye el pago total que por estas mercancías ha hecho o vaya a hacer efectivamente el comprador al vendedor, de manera directa y/o de manera indirecta en beneficio del mismo vendedor.

3. Los pagos directos deben estar reflejados en las facturas comerciales o contratos correspondientes a las mercancías importadas (...).

\section{Artículo 3o. Costo del Seguro.}

1. El importe que debe consignarse por el costo del seguro, es el correspondiente a la prima efectivamente pagada por este concepto. En ningún caso se aceptará una declaración de valores teóricos o estimados o que no tengan soporte documental alguno.

2. El seguro se refiere al costo del servicio necesario para cubrir los riesgos de daños o pérdidas durante el transporte, carga, descarga y manipulación de las mercancías hasta el lugar de importación.

3. El documento con el cual se demuestra el costo del seguro es la póliza expedida por la compañía aseguradora o certificado de aplicación de póliza individual. 
los seguros de personas y a los seguros de daños; dentro de los segundos podemos también diferenciar aquellos denominados seguros reales y los nombrados seguros patrimoniales. Es a esta segunda gran clasificación, a los seguros de daños, a que se circunscribirá cuando de analizar la naturaleza y circunstancias propias del interés asegurable se refiera, en tanto, bien es sabido, dicha categoría, en el escenario de los seguros de personas, despierta y genera una profusa cantidad de criterios, conceptos y doctrinas en nada pacíficos, y que no interesan para el objeto del presente estudio.

\subsubsection{Interés asegurable como elemento del contrato de seguro en el marco de} la compraventa internacional de mercaderías y los INCOTERMS. Como elemento esencial o como requisito de validez, el interés asegurable junto con el riesgo asegurable, la prima y la obligación condicional hacen parte del contrato de seguro. En Colombia es la propia ley mercantil (art. 1045) la que de manera expresa lo consagra como un elemento de la esencia, sin el cual no puede hablarse de la existencia del contrato o por lo menos de su eficacia, lo cual no resulta indiferente si se tiene en cuenta que, conforme con el artículo 897, la ineficacia opera de pleno derecho sin que se requiera declaración judicial.

ARTÍCULO 1045. ELEMENTOS ESENCIALES. Son elementos esenciales del contrato de seguro:

1) El interés asegurable;

2) El riesgo asegurable;

3) La prima o precio del seguro, $y$

4) La obligación condicional del asegurador.

En defecto de cualquiera de estos elementos, el contrato de seguro no producirá efecto alguno.

El interés asegurable en los seguros de daños se corresponde con la relación o vinculo económico, en que se encuentra una persona con un bien o derecho tomados en sentido general o particular ${ }^{2}$ (Ossa, 1991, p. 73 ).

2 El mismo Ossa (1991, p. 73) describe, con base en la definición de interés asegurable, los tres pilares sobre los cuales descansa el concepto: "el sujeto, que es la persona natural o jurídica amenazada en la integridad de su patrimonio, el objeto, que es un bien sobre el que recae la amenaza del riesgo y la relación económica entre uno y otro que puede resultar afectado por la realización del riesgo". El bien sobre el cual recae el riesgo también puede ser un derecho o una universalidad como el patrimonio mismo. 
Rodríguez Rodríguez (1978) citado por López Blanco (2004, p. 79) lo define como el “(...) vínculo económico en virtud del cual la necesidad económica que provoca la producción del riesgo repercute desfavorablemente en un determinado patrimonio"3.

El Código de Comercio colombiano en el artículo 1083 establece que "tiene interés asegurable toda persona cuyo patrimonio pueda resultar afectado, directa o indirectamente, por la realización de un riesgo. Es asegurable todo interés que, además de lícito, sea susceptible de estimación en dinero", de lo que desde ya puede desprenderse que el interés asegurable puede corresponder o recaer en quien tiene una relación económica directa con el bien, como el propietario, usufructuario, poseedor, o en quien concurre una relación indirecta con el mismo, en tanto su patrimonio de manera general puede verse afectado con el riesgo que amenace potencialmente el bien. Pero, así mismo, se insiste, esa relación o vinculo puede darse de manera concreta sobre un bien o derecho determinado o sobre una universalidad como el patrimonio mismo. Es esta delimitación la que permite distinguir entre los seguros reales (directos, puros o de facultad) y los seguros patrimoniales (como el de responsabilidad).

Efectivamente, si se toma como ejemplo una casa, pueden tener intereses asegurables sobre ella, entre otros: el propietario, el arrendatario, el acreedor hipotecario, quienes pueden contratar un seguro que proteja sus diversos intereses pero sin que sea posible, en principio, ante la ocurrencia de un siniestro, aspirar a que se pague una suma mayor del valor de la casa en el momento del siniestro, de acuerdo con la discutible limitación que impone el art 1084. (López Blanco, 2004, p. 80) ${ }^{4}$

Así, el límite de indemnización solo al valor del bien se constituye únicamente en principio, esto por cuanto pueden haber aspectos que lo superen como el referente al lucro cesante que en Colombia debe ser objeto de pacto expreso, claro está, guardando estrecha correspondencia con el principio indemnizatorio propio y esencial a los seguros de daños como lo viene a establecer el artículo $1088^{5}$ y el propio $1084^{6}$.

3 Este mismo autor cita el concepto que Ehrenberg tiene del interés así (Ossa, 1991): "la relación a partir de la cual alguien sufre un daño patrimonial a consecuencia de un hecho determinado".

4 Sin embargo, Ossa (1991, p. 79) "Según la naturaleza de la relación. El interés asegurable puede ser independiente o, mejor aún, excluyente, como el que se sustenta en el dominio pleno de la cosa asegurada. $\mathrm{O}$ concurrente, según lo expuesto en otra parte de este capítulo”.

5 ARTÍCULO 1088. <CARÁCTER INDEMNIZATORIO DEL SEGURO>. Respecto del asegurado, los seguros de daños serán contratos de mera indemnización y jamás podrán constituir para él fuente de enriquecimiento. La indemnización podrá comprender a la vez el daño emergente y el lucro cesante, pero éste deberá ser objeto de un acuerdo expreso.

6 Acerca de una interpretación pro interés asegurable, en el sentido en que siempre que haya dudas en torno a la declaración de interés asegurable como elemento esencial del contrato de seguro, se opte por inclinarse a 
Esa misma previsión, de forma menos expresa, puede desprenderse de lo establecido en los artículos $1042^{7}$ (referente al seguro por cuenta ajena) y $1124^{8}$ (en relación con el seguro de transporte), en tanto se refieren a la concurrencia o sucesión de intereses asegurables en diferentes personas, dependiendo del vínculo jurídico-económico que mantengan con el bien o derecho' .

\section{$\mathrm{Al}$ respecto del interés asegurable, el ilustre profesor Efrén Ossa comentando} sentencia de la Corte Suprema de Justicia de Colombia, de febrero 12 de 1977. MP Héctor Roa Gómez. Jurisprudencia civil Tomo IV, núm. 1491. P 1928. (Asociación Colombiana de Derecho de Seguros [ALCOLDESE], 2007, p. 300) manifestó:

favor de este. En el caso In Stock v Inglis (1884) 12 QBD 564 at 571 Brett MR:-“In my opinion it is the duty of a Court always to lean in favour of an insurable interest, if possible, for it seems to me that after underwriters have received the premium, the objection that there was no insurable interest is often, as nearly as possible, a technical objection, and one which has no real merit, certainly not as between the assured and the insurer". Refiriéndose este caso a la negativa de una aseguradora a pagar la indemnización por cuanto en el contrato de compraventa no se había establecido el traspaso de la propiedad del comprador al vendedor, siendo el comprador quien reclamaba. En "Passing of Risk in international sale contracts: A comparative examination of the rules on risk under the United Nations Convention on Contracts for the International Sale of Goods (Vienna 1980) and INCOTERMS 2000". En Valioti (2003).

7 ARTÍCULO 1042. <SEGURO POR CUENTA >. Salvo estipulación en contrario, el seguro por cuenta valdrá como seguro a favor del tomador hasta concurrencia del interés que tenga en el contrato y, en lo demás, con la misma limitación como estipulación en provecho de tercero.

8 ARTÍCULO 1124. <PERSONAS QUE PUEDEN CONTRATAR EL SEGURO DE TRANSPORTE>. Podrá contratar el seguro de transporte no sólo el propietario de la mercancía, sino también todos aquellos que tengan responsabilidad en su conservación, tales como el comisionista o la empresa de transporte, expresando en la póliza si el interés asegurado es la mercancía o la responsabilidad por el transporte de la mercancía.

9 Sánchez Palacios (2007, p. 22) en relación al origen de la disposición en Colombia: "El subcomité de seguros, asesor del comité para la revisión del código de comercio, que fue el responsable de la redacción del título V, del libro cuarto del citado código que regula al contrato de seguro, quiso en un principio que la norma contuviese a título enunciativo, casos de interés asegurable; es así como el articulo sub-examine que correspondía al 901 del proyecto inicial, decía originalmente: "'El interés asegurable deberá ser susceptible de estimación en dinero. Tiene interés asegurable toda persona cuyo patrimonio pueda resultar afectado, directa o indirectamente, con la ocurrencia del riesgo. Así tienen interés asegurable:

1. El titular de un derecho real, llamase propietario usufructuario, acreedor hipotecario o prendario, o de cualquier otro modo.

2. Toda tenedor o contractualmente obligado a responder por la conservación de un bien o conjunto de bienes, en su calidad de arrendatario, comodatario, administrador y otra semejante.

3. Toda persona que pueda incurrir en responsabilidad contractual o extracontractual por sus propias culpas o por las de las personas que de ella dependan.

4. Todo aquel que tenga un germen objetivamente razonable de ganancia licita, con tal que esta sea susceptible de estimación en dinero.

5. El asegurador en los riesgos que asuman en su calidad de tal.

6. Esta enumeración es simplemente enunciativa”. 
(...) con singular acierto, precisa que no hace falta probar el dominio para configurar el "interés asegurable" sobre la cosa asegurada, basta por ende probar su compra y la posesión de ella en el momento del siniestro. Y que la explotaba por su cuenta desde que el vendedor le hizo la entrega correspondiente. "En efecto -agrega la sentencia-, en los seguros de daños tiene interés asegurable toda persona cuyo patrimonio puede resultar afectado, directa o indirectamente, por la realización de un riesgo, como a la letra lo dice el artículo 1083 del C. de Co. Ahora bien, como de conformidad con el artículo 929 ibídem, desde cuando el comprador recibe la cosa comprada cesa la responsabilidad del vendedor por su pérdida, es claro que O.V.I. tenía pleno interés en el contrato de seguro contra robo, pues en el caso de presentarse el siniestro, que efectivamente ocurrió, su patrimonio resultaría seriamente afectado por la realización del riesgo.

El interés asegurable, por tanto, no se identifica con su objeto, lo que permite hablar con más confianza de concurrencia de intereses asegurables, no obstante que algunos como Halperin (1946) identifiquen al interés asegurable con el objeto del contrato de seguro.

Podemos ir precisando entonces que esa dualidad de concepto inmanente al interés asegurable en cuanto a la relación directa o indirecta, permite deducir que este, en los seguros de daños, y muy especialmente en los seguros reales, descansa no solo en el propietario del bien, sino también en cualquier otra persona que pueda ver afectado su patrimonio con su pérdida. Es esto lo que permite deducir, en el campo de la compraventa, y más específicamente en el de la compraventa internacional de mercaderías regulada por la Convención de Viena, que tanto el comprador como el vendedor tienen interés asegurable sobre las mercaderías objeto del contrato, aun independientemente de que se haya o no verificado la transferencia de la propiedad.

El interés asegurable entonces, es un concepto más económico que jurídico, en tanto está relacionado directa o indirectamente con el patrimonio del sujeto asegurado. Al decir de Gallego Sánchez (2003, p. 1558):

El interés se define como la relación de contenido económico entre un sujeto y un bien, la cual tiene un valor cuya disminución o pérdida será compensada con la indemnización del seguro. Tal relación puede tener una configuración jurídica muy variada (propiedad, usufructo, depósito...); pero lo determinante no es el aspecto jurídico de la misma, sino la relación de hecho entre el sujeto y el bien y en la medida en que en virtud de la misma el sujeto pueda sufrir un daño al realizarse el determinado evento. Conforme a ello también, en la medida en que sobre un 
mismo bien pueden recaer intereses diversos (del propietario, del arrendatario...); también pueden existir varios seguros sobre un mismo bien.

Sigue aclarando Ossa (1991, p. 80) acerca de esta misma preponderancia económica sobre lo jurídico:

Si el interés es económico, no importa que no sea, a la vez, un interés jurídico. El poseedor, v. gr., con justo título y buena fe -el poseedor regular- tiene interés asegurable en la cosa y puede asegurarla como si fuera su dueño. Si la cosa parece para el acreedor (res perit creditore), este tiene en ella un interés asegurable, no importa que aún no sea su dueño, porque su pérdida puede aparejarle un prejuicio económico. El titular de un derecho personal, el acreedor quirografario, tiene interés asegurable en el único bien de su deudor, aunque no sea acreedor prendario, porque ese bien constituye garantía de su acreencia.

Como vimos en su oportunidad, en ninguno de los contratos de compraventa de que pueda dar cuenta régimen jurídico alguno se presentan tantas posibilidades temporales o cronológicas en cuanto a las tres posiciones jurídicas principales que se pueden presentar con respecto a la mercancía, esto es, la entrega, la transmisión del riesgo por la pérdida de estas y la transferencia del derecho de dominio (tradición). Es por ello que la sola insinuación doctrinal, jurisprudencial o legal tendiente a hacer descansar exclusivamente en el campo del dominio al interés asegurable en los seguros reales, trae consigo graves consecuencias en materia de inseguridad jurídica que conducen - de hecho se ha producido- a la aparición de no pocos litigios. No han sido pocos los casos en los que las compañías aseguradoras han decidido objetar el pago del valor asegurado por las mercancías en contratos de compraventa por el solo hecho de no descansar la titularidad del dominio en la persona del beneficiario-asegurado.

3.1.2 Jurisprudencia nacional. No obstante, la jurisprudencia nacional no ha dado paso para que se abra camino esta posición. Desde que se viene planteando como excepción por parte de las compañías aseguradoras en los procesos judiciales de esta clase, con algunas vacilaciones de tipo simplemente semántico, se ha venido sentando y acentuando la amplitud que el concepto de interés asegurable comporta, recalcando también el carácter preponderante de la relación económica sobre la relación jurídica del sujeto asegurado con el objeto, lo que permite deducir un interés asegurable de relaciones simplemente tenenciales (arrendatario) o de obligaciones estrictamente personales (acreedor, no necesariamente hipotecario ni prendario). 
En fallo del 12 de febrero de 1977, la Corte Suprema de Justicia deja claro que no hace falta que se consolide la propiedad para probar el interés asegurable sobre la cosa asegurada, conformándose con que se pruebe su compra y la posesión al momento del siniestro.

Sin embargo, en sentencia de agosto 28 de 1978, la misma corporación, a instancia del artículo 1107, referente a la cesión del objeto del interés asegurado, es decir del bien asegurado y la extinción que dicha transferencia de la propiedad produce, propició con alguna falta de precisión conceptual, que se abran paso posiciones que en la práctica, se reitera, producen peligrosa inseguridad en el tráfico mercantil; dado que compradores y vendedores se verán potencialmente sometidos a que una filigrana técnica impida la protección de sus intereses, derrumbando una falsa seguridad que creerían tener al amparo de una póliza de seguro sobre su mercancía. Esto, por cuanto concluye sin miramientos la extinción del contrato por la transmisión del objeto del interés.

En sentencia del 13 de agosto de 1990 del Consejo de Estado (AC-44), se trató el interés abstracto que puede estar presente en la póliza automática al amparo del artículo 1050 de Código de Comercio:

Pese a tener características propias, la póliza automática no difiere de la póliza común ni en su naturaleza jurídica ni en sus elementos constitutivos. Es simplemente suigéneris en cuanto no requiere para su validez de formalidades tales como la identificación o valoración de los intereses del contrato, lo que no significa que no tenga interés asegurable: lo tiene, pero se consigna en el certificado de seguro o "por otros medios sancionados por la costumbre", según enseña el artículo 1050 del Código de Comercio" (...). "En la póliza automática aparecen definidos en abstracto el interés y el riesgo asegurables y consignadas las condiciones generales del seguro”.

En fallo del 22 de enero de 1991 también en relación con la póliza automática se estableció la presencia de interés asegurable:

Si por interés asegurable es menester entender la relación de contenido patrimonial existente entre quien solicita el seguro y el bien sobre el cual éste ha de recaer legal es admitir que este elemento está presente en la póliza automática desde cuando ella se suscribe por el asegurador, pues desde entonces se convienen con éste, así sea de manera general, los efectos de carácter económico que se van a proteger". (...) "claramente lo dice el artículo 1083 del C. de Co., "tiene interés asegurable toda persona cuyo patrimonio pueda resultar afectado, directa o indirectamente, 
por la realización de un riesgo...”. Por eso, cuando en una póliza automática se contrata, por ejemplo, la cobertura del transporte de mercancías que le remiten a un comerciante desde el exterior, ya existe un interés asegurable que es real y no mera expectativa.

En sentencia del 14 de diciembre de 2000, se reconoce la multiplicidad de daños que se pueden presentar sobre un mismo objeto o derecho que consecuentemente afectan intereses asegurables autónomos:

Esto significa que la unidad es predicable respecto del siniestro, pero con el cual puede ocasionarse una multiplicidad de daños, los que a su turno pueden afectar el interés asegurable en los términos del artículo 1083 del Código de Comercio, (sic) los que por su independencia, identidad jurídica y autonomía están llamados a recibir procesalmente para su reconocimiento un tratamiento separado igualmente autónomo e independiente que no requiere resolución uniforme (...).

En fallo del 7 de mayo de 2002, la Corte reconoce la presencia de interés asegurable en el acreedor ${ }^{10}$ de una obligación de carácter personal: "Consecuentemente con su naturaleza y con el fin que está llamado a cumplir, en tal modalidad contractual el asegurado no puede ser otro que el acreedor de la obligación, pues únicamente en él radica un interés asegurable de contenido económico: que el riesgo que envuelve el convenio, quede garantizado".

En fallo del 30 de septiembre de 2002, que podría catalogarse como hito sobre la materia, en relación con el seguro de transporte y al seguro por cuenta ajena, regulados en los artículos 994 y 1124, el primero, y 1042 el segundo, la Corte realiza una serie de precisiones en torno al interés asegurable presente en el seguro de transporte y puntualiza cómo este tipo de seguros se refiere a uno patrimonial cuando el asegurado es el transportador, en cuanto lo que se asegura es la responsabilidad de este por el cumplimiento de sus obligaciones en la ejecución de dicho contrato de transporte y no la pérdida de los bienes en sí mismos, puesto que, aduce la Corte, no habrá interés asegurable en el transportador sobre la mercancía misma, aun teniendo en cuenta que es obligado a su conservación. Dicha categoría de interés asegurable -directo sobre los bienes- se predica del propietario (al tenor del artículo 994), o de las demás personas interesadas en la conservación de la mercancía, como pueden ser el remitente o el destinatario de esta por su interés en su conservación o, incluso, como acreedores de

10 En este mismo sentido y con respecto a los seguros de cumplimiento, se encuentran sentencias del 15 de marzo de 1983, 21 de septiembre de 2000, exp. 6140, 22 de julio de 1999, exp. 5065; 26 de octubre de 2001, exp. 5942; 2 de mayo de 2002, exp. 6785. 
una obligación personal consistente en entregar la mercancía o pagar el precio de esta dentro del contrato de compraventa ${ }^{11}$.

Es obvio que la prenotada relación, indefectiblemente, no supone vínculo de origen dominical, en razón de que ella puede darse respecto a ligámenes de naturaleza y génesis diversa, v. gr., de índole tenencial. Es lo que sucede, justamente, en punto al usufructo, al depósito, al arrendamiento, al "leasing”, etc.

Por ello es por lo que en el campo específico del seguro de transportes, no puede atribuírsele al dueño de las mercancías transportadas la titularidad exclusiva -y excluyente- del interés asegurable, como quiera que otros sujetos, por igual, separada o conjuntamente, bien pueden investirlo.

Ello explica que el artículo 1124 del Código de Comercio, reafirmando el señalado aserto, disponga que, "Podrán contratar el seguro de transporte no sólo el propietario de la mercancía, sino también todos aquellos que tengan responsabilidad en su conservación, tales como el comisionista o la empresa de transporte" (el subrayado es ajeno al texto original).

Si tiene lugar lo primero, esto es que de alguna manera se explicite -o se haga inteligible- que el interés asegurable recae sobre la mercancía, es dable partir de que el seguro tomado por el transportador, por regla, gracias al régimen especial colombiano, tiene un doble cometido: proteger un interés propio y, al mismo tiempo, en forma preferente, a la par que convergente, uno ajeno (seguro por cuenta ajena, C. de Co., art. 1042), tal y como luego se aludirá, a espacio, dado que en Colombia esta modalidad de contratación, que se opone a la que se realiza por cuenta propia (C. de Co., arts. 1037 y 1040), tiene un radio de acción mayor, al punto que si no se estipula lo contrario, “...el seguro por cuenta valdrá como seguro a favor del tomador hasta concurrencia del interés que tenga en el contrato y, en lo demás, con la misma limitación, como estipulación en provecho de tercero" (C. de Co., art. 1042).

"El interés asegurable en el seguro de transporte cuando el transportador es el tomador, el asegurado y el beneficiario, no puede ser distinto del que natural y

11 Al respecto Ossa (1991, p. 512): “Debemos entender que, aunque jurídicamente los riesgos se trasladan al comprador por ministerio de la ley (desde el momento de la entrega material), económicamente continúan gravitando sobre el patrimonio del vendedor en la medida de la parte insoluta del precio de la obligación. Y que, por tanto, subsiste en su cabeza un interés asegurable. Supuesta la insolvencia del comprador en caso de siniestro, o su renuencia al pago, el patrimonio del vendedor puede resultar afectado, directa o indirectamente por la realización de un riesgo, como reza textualmente el art. 1083 del código de comercio. El interés asegurable es un concepto económico y, como tal, es objeto del seguro". 
verdaderamente corresponde, esto es, la responsabilidad por el transporte de la mercancía, así se hubiese consignado en la póliza uno diferente. Ello significa, a términos del artículo 84 de la Ley 45 de 1990, que el propietario de la mercancía es el beneficiario de la indemnización si [se] presenta el siniestro, evento ante el cual el artículo 87 de la misma ley lo faculta para iniciar acción indemnizatoria directa contra el asegurador, dentro de la cual, con citación del transportador, deberá acreditar la responsabilidad de éste. En otras palabras, el transportador sólo puede tener interés asegurable en presencia de un seguro de responsabilidad civil, así el efectivamente suscrito se designe como de transporte.

No es, pues, que el artículo 1124 del Código de Comercio, en los términos en que lo modificó el Decreto 01 de 1990, haya establecido un interés asegurable común entre el propietario de las mercancías a transportar y todos aquellos que tengan interés en su conservación. No, lo que ha de entenderse lógica y racionalmente del sentido de esa norma es que, a más de mediar un diverso interés en uno y otro evento (es lo que se deduce del mandato de exteriorizar el interés), cada una de esas personas puede contratar el seguro de daños expresando, según sea el caso, cuál es el suyo en particular, sin que la omisión al respecto desnaturalice el acuerdo de voluntades, ni mucho menos tenga que entenderse que establece una identidad de interés asegurable, porque obviamente en unos eventos será directo y en otros indirecto, con las respectivas consecuencias inherentes.(Corte Suprema de Justicia. Sentencia de septiembre 30 de 2002) $)^{12}$

El fallo cita doctrina del tratadista español Juan Luis Pulido Beguines, para afirmar y sustentar que no tiene interés asegurable en el contrato de seguro de daños (puro o de facultades) el transportador en los bienes que transporta (aun, claro está interesado en la conservación de los mismos), puesto que este interés solo corresponderá a uno de carácter patrimonial, dado que solo en la medida de la afectación que pueda producir en su patrimonio la declaratoria de responsabilidad podrá entenderse acaecido el riesgo (concretado el siniestro):

(...) si el porteador, el comisionista de transportes o las agencias de transporte lo que aseguran es su propio interés en la conservación de las mercancías, y no el del cargador o consignatario de la carga, nos encontraremos ante un seguro de responsabilidad civil, aun cuando la cobertura se realice a través de una póliza de facultades. Si el interés que se asegura es el del porteador, el contrato no es de seguro de daños a las cosas, sino un seguro de la responsabilidad de éste.

12 Igual materia se trata en la sentencia del 19 de nov. 2001, Exp. 5978, de la misma Corporación. 
Posición que es asumida íntegramente por la Corte, la que incluso desglosa las cláusulas contractuales aseguraticias en el caso concreto, para develar el carácter patrimonial y no real de dicho seguro; así por ejemplo, el hecho de que se haya pactado la fuerza mayor y el caso fortuito de manera expresa como riesgos objeto de cobertura llevó necesariamente a concluir que no podría estar amparada la responsabilidad civil, puesto que, según el fallo, ambos son certeramente causas de exoneración de la responsabilidad civil. Similar análisis con conclusiones semejantes en torno al seguro de transporte y la doble connotación del interés asegurable realiza Guzmán Escobar (2009, p. 164) citando también a Ordóñez (1993).

La misma precisión que realiza la corte en cuanto al contrato de transporte cabría hacerla en cuanto a los demás contratos que implican una obligación de conservación de la cosa, es decir, todos estos sujetos tienen interés asegurable de carácter patrimonial y no real sobre las mercancías, en tanto su patrimonio solo se verá afectado por su pérdida en la medida en que se declare su responsabilidad, y en esa misma medida, se afecte su patrimonio. Es el caso del arrendatario -y de cualquier otro tenedor- quien está obligado a la entrega y a la conservación de la cosa, pero no a correr con los riesgos de su pérdida fortuita y quien responderá solo en la medida en que así sea declarado bajo el régimen de culpa imperante en el derecho privado. Pero más aún, puede concluirse, bajo está misma premisa, que ni el vendedor ni el comprador -en el contrato traslaticio- tienen interés asegurable de carácter real, en los términos en que se viene planteando, sobre la mercancía hasta o desde cuando se hagan cargo del riesgo ${ }^{13}$.

Lo anterior no es poca cosa, si se tiene en cuenta que, quien no corre con el riesgo de la pérdida fortuita del cuerpo cierto solo responderá en la medida de su culpa, o por lo menos de la mora en la que se encuentre, y que por tanto, la pérdida de los bienes solo le traerá un perjuicio económico cuando se declare dicha responsabilidad. No debe perderse de vista que el interés asegurable (o asegurado -una vez que se ejecute el contrato-) debe ser permanente durante toda la vigencia del mismo (artículo $1086^{14}$ del Código de Comercio). Así López Blanco (2004, p. 79): "El interés asegurable debe existir permanentemente durante toda la vigencia del contrato, y en caso de que aquel

13 Textualmente, Guzmán Escobar (2009, p. 177): “Como el transportador no tiene interés asegurable (directo) sobre las mercancías, sino que su interés asegurable radica en la eventualidad de ser declarado civilmente responsable del daño, pérdida o retraso de las mismas, bien podría suceder que una compañía de seguros objete el pago de la indemnización, invocando la nulidad del contrato por no existir interés asegurable en cabeza del asegurado que, recordemos, es el transportador y no el remitente/ destinatario/ propietario de las mercancías. En tal evento, entonces, la cobertura seria inocua y al remitente o destinatario solo le quedaría el camino de procurar un reconocimiento de la responsabilidad por parte del transportador".

14 ARTÍCULO 1086. <EXISTENCIA DEL INTERÉS Y EXTINCIÓN>. El interés deberá existir en todo momento, desde la fecha en que el asegurador asuma el riesgo. La desaparición del interés llevará consigo la cesación o extinción del seguro, sin perjuicio de lo dispuesto en los artículos 1070, 1109, 1111. 
desaparezca, termina el seguro (art. 1086 del C. de Co.), por ello se explica que cuando un bien se enajena y el nuevo propietario no contrata, el seguro se extingue, como sucede, por ejemplo, en el seguro de automóviles; y es obvio que el asegurador tiene derecho a que se le pague la prima hasta la fecha en que se produjo la terminación por extinción del interés asegurable (...)”.

No resulta menos importante el hecho de que el artículo 994 del mismo estatuto mercantil se refiera concretamente al propietario de las mercancías para especificar el contrato que deberá perfeccionar el transportador para cubrir los riesgos del transporte de estas, acentuando aún más la confusión. Al respecto, se observa en el fallo que venimos considerando:

En adición a lo anterior, el artículo 994 del Código de Comercio, reformado por el artículo 12 del Decreto 01 de 1990 -decreto que a su turno modificó el artículo 1124 del Código de Comercio-, es categórico al refrendar que el instituto del seguro por cuenta ajena, in concreto, es aplicable al seguro de transporte. Es así como dispone, ad pedem litterae, que

"Cuando el gobierno lo exija, el transportador deberá tomar por cuenta propia o por cuenta del pasajero o del propietario de la carga un seguro que cubra a las personas o a las cosas transportadas contra los riesgos inherentes al transporte“(el subrayado no es original).

Sobra puntualizar que en el caso sub examine (segunda hipótesis), el transportador, a diferencia de lo acaecido en la primera de ellas, carece por completo de interés asegurable, de tal forma que, en procura de salvaguardar el de un tercero, titular de las mercaderías, es que justamente procede a la contratación del seguro de transporte, propiamente dicho -tradicional o puro-, en el que el seguro de responsabilidad civil nada tiene que ver. De ahí que no sea el asegurado, sino únicamente el tomador, lo que de paso, excluye la calidad de beneficiario.

Sin embargo, la Corte Constitucional, en sede de tutela, mediante fallo del 31 de octubre del mismo 2002, se manifestó en contravía de las anteriores, reseñadas, conclusiones del máximo Tribunal Civil, expresando que el depositario como encargado de la conservación de las mercancías, con base en el artículo 1124 ya aludido, tenía un interés real y no patrimonial sobre las mismas (Corte Constitucional. Sala octava de revisión. Sentencia T-924 de 2002. Ref.: Expediente T-621.437. Magistrado Ponente: Dr. Álvaro Tafur Galvis): 
Y, hasta donde está probado, la antes nombrada y Colseguros S.A. convinieron en amparar mercancías en tránsito, no que la aseguradora asumía y la asegurada trasladaba un riesgo patrimonial; ${ }^{(7)}$ puesto que para que en una póliza de transporte opere este amparo, al tenor de lo reglado en el artículo 1124 del Código de Comercio, debe pactarse expresamente,(8) y la póliza de transporte objeto del reclamo nada dijo al respecto.

(7) El artículo 1082 del Código de Comercio clasifica los seguros de daños o de personas; y aquellos, a su vez, en reales o patrimoniales. Los artículos 1120 y 1127, por su parte, disponen i) que el seguro de transporte comprenderá lodos los riesgos inherentes al mismo, y ii) que el seguro de responsabilidad impone a cargo del asegurador la obligación de indemnizar los perjuicios patrimoniales que cause el asegurado con motivo de determinada responsabilidad en que incurra de acuerdo con la ley; y que este último tiene como propósito el resarcimiento de la víctima, la cual, en tal virtud, se constituye en el beneficiario de la indemnización, sin perjuicio de las prestaciones que se le reconozcan al asegurado.

(8) El artículo 1124 del Código de Comercio, sobre la contratación del seguro de transporte dispone: "Podrán contratar el seguro de transporte no sólo el propietario de la mercancía, sino también todos aquellos que tengan responsabilidad en su conservación, tales como el comisionista o la empresa de transporte, expresando en la póliza si el interés asegurado es la mercancía o la responsabilidad por el transporte de la mercancía" -artículo 46 del D.E. 01/90-.

De tal suerte que todo indica que la asegurada contrató una póliza de valor real para atender los daños sufridos por las mercancías en tránsito bajo su custodia, evitando a sus clientes tener que acudir a un proceso para ser indemnizados, salvaguardando de esta manera su prestigio de depositario profesional.

Siguiendo con los fallos sobre la tradición de la propiedad y su relación con el interés asegurable, tenemos decisión del 21 de marzo de 2003, en la que, apoyados sobre la sentencia hito del 30 de septiembre de 2002, reitera la doctrina del interés diverso, concurrente y sucesivo y no necesariamente amarrado al derecho de dominio: "el interés asegurable atañe a una cierta relación económica, no resulta indispensable que coincidan la persona o personas involucradas en ella con quienes son los titulares del derecho de dominio como principal relación jurídica predicable del bien afectado con la realización del riesgo, mucho más, si inclusive el interés puede ser indirecto, como expresamente lo consigna la ley comercial. Así por ejemplo, dependiendo de 
las circunstancias, podrían tener interés asegurable el dueño y el poseedor material de la misma cosa, o el dueño y el usufructuario".

En marzo 10 de 2005, y en relación con la trasferencia del interés asegurable o del objeto de este -tema que se abordará más adelante- la Corte Suprema reitera la presencia de aquel en el comprador que aún no se ha hecho titular del dominio de los bienes: "Al asegurador, por tanto, lo que le interesa saber es quién es el adquirente del bien asegurado, por ser esta una de las primordiales causas para contratar. "El hecho de que esté pendiente un acto diferente y consecuencial como la tradición no significa que no exista una relación económica entre el comprador y el bien, que precisamente constituye el interés asegurable que tiene la nueva persona con quien el asegurador no desea contratar".

En fallos del 25 de enero y del 16 de mayo de 2008, la Corte Suprema, basándose en la sentencia hito ya mencionada, se reitera en la diversidad y concurrencia de intereses asegurables y en el carácter no exclusivo del propietario como interesado en la conservación de los bienes: "Tal acontecería al concurrir el "interés asegurable” del dueño y del poseedor material de la misma cosa, o el de aquel y el del usufructuario; la sociedad que sufre directamente la pérdida y sus socios que indirectamente pueden verse afectados. En cada una de estas hipótesis todos los sujetos tendrían, en su medida, una utilidad pecuniaria lícita y nada les impediría, entonces, que por medio del contrato de seguro cualquiera de ellos pretendiera cubrirse de las secuelas dañinas de un riesgo que, derechamente o por reflejo, alcance a significarles un menoscabo patrimonial”.

De una posición contraria nos encontramos un ejemplo en la jurisprudencia china, en la que de manera expresa se contempla el título de dominio como requisito necesario para que concurra interés asegurable en el ámbito de la compraventa internacional de mercaderías (Wuhan Maritime Court. Nanjing Resources Group v. Tian An Insurance Co. Ltd. Nanjing Branch. 10 September 2002. Translation by Zheng Xie.Edited by William Zheng):

La discusión se centró precisamente en la naturaleza del interés asegurable y la titularidad de este en el comprador que aún no se ha hecho dueño o propietario de las mercaderías. Esto, independientemente del INCOTERMS pactado. El problema jurídico consistió en determinar (i) si la propiedad y el riesgo sobre las mercancías son inseparables el uno del otro, solo el propietario de las mercancías en general tiene el interés asegurable, o si (ii) antes de que la propiedad de los bienes se transfieran al comprador, este no tiene un interés asegurable en ellos. 
Esto luego de pasar por el análisis de la trasferencia de los riesgos a partir de la entrega que el vendedor hace al comprador en los términos en que se establece en la Convención de Viena.

El Asegurador, alegó que cuando la embarcación se hundió y se produjo la pérdida, el comprador no tenía ningún interés asegurable, por lo que el Asegurador tenía derecho a rechazar la reclamación conforme al artículo 11 de la Ley de Seguros de la República Popular China que estipula: "El solicitante deberá tener un interés asegurable en el objeto asegurado. El contrato de seguro será nulo y sin efecto si el demandante no tiene interés asegurable en el objeto asegurado"15.

El Tribunal de Justicia chino declaró que si el asegurado bajo una póliza de seguro tiene un interés asegurable debe ser determinado por el hecho de que este tiene la propiedad de la mercancía cuando la pérdida se produce si el asegurado legalmente está en posesión del certificado de propiedad. El conocimiento de embarque representa los bienes, por lo que la venta del conocimiento de embarque es igual a la venta de los bienes. Desde el punto de vista jurídico, la transferencia de un conocimiento de embarque implica la transferencia de la propiedad ${ }^{16}$. La parte propietaria de las mercancías debe mantener el conocimiento de embarque, la parte que desea obtener el conocimiento de embarque debe pagar el valor (pagar el precio del contrato) para obtener dicho conocimiento de embarque. El vendedor en este caso no entregó las mercancías ni recibió el pago de acuerdo con los documentos. El comprador no hizo el pago de acuerdo a estos documentos; por lo tanto, el contrato de venta no se realizó y la transacción no se produjo; cuando se produjo la pérdida de la mercadería, el comprador no tenía legalmente los conocimientos de embarque, por lo que no tenía ningún interés asegurable.

En conclusión, el Tribunal, teniendo en cuenta que el comprador y el asegurador celebraron el contrato de seguro de transporte marítimo y que el comprador y el vendedor no perfeccionaron la transferencia de la propiedad vía entrega de los documentos de transporte (conocimiento de embarque), decretó la nulidad del contrato de seguro con base en el artículo 11 (2) de la Ley de Seguros de la República Popular China ya transcrito, obligando al asegurador solo al reembolso de la prima.

15 Se debe recordar que en Colombia la falta de interés asegurable no produce nulidad, sino inexistencia del contrato de seguro.

16 Similar tratamiento del conocimiento de embarque como título valor representativo de las mercaderías. 
También sobre la misma materia, pero en sentido contrario, el Tribunal Supremo español, con base en sentencia del 17 de junio de 1982, se pronuncia en tres oportunidades posteriores (STS 15 de junio de 1988, STS 8 de marzo de 1990 y STS 31 de diciembre de 1996), sentando que el dominio concurre con las demás relaciones jurídico-económicas del sujeto asegurado con los bienes, para desprender de ello el interés asegurable como elemento o requisito de validez del contrato de seguro. En la STS del 31 de diciembre de 1996, sobre este punto se expresa:

La cuestión que se plantea en el motivo no se circunscribe a la manifestación que hace la sentencia, en el fundamento de derecho segundo, cuando dice: "la demandada se opone al pago por entender, de un lado, que el demandante carece de interés al no ser propietario del buque", ya que la recurrente nunca ha dicho que el interés en el seguro sea equivalente a ser propietario del buque, al aceptar que pueda tener interés no sólo el propietario, sino, además, el acreedor hipotecario, etc., es decir, todo aquel que tenga un interés, en el concepto económico, y así, la sentencia del 17 de junio de 1982, dice que el interés es la ventaja que la no producción del resultado dañoso representa para el asegurado. La cuestión planteada es que "Pandomar S.A." no tenía ningún interés económico acreditado en el buque "Constant Hope". El buque se vendió antes del siniestro, (motivo primero). En la sentencia recurrida se ignora el principio fundamental referido a la carga de la prueba, de incumbir al demandante la prueba de los hechos constitutivos de su pretensión, y dicha sentencia encuentra el interés de "Pandomar S.A." en que era quien explotaba el buque, lo cual no se prueba en ninguna parte del pleito por la actora y solo se llega por la audiencia a la vista de que "hubo de afrontar el importe de las reparaciones" lo que desde luego no tiene justificación alguna cuando el barco ya se había vendido al Sr. Mallo y otros, y, además, "Pandomar S.A." solo se dedicaba a importar y a comercializar pescado y productos del mar, incluso, sin que se pruebe, ni tan siquiera tal obligación-.(..) Si a tenor de tales hechos: "Pandomar S.A." concertó de un contrato de seguro de cobertura de daños del buque "Constant Hope", cuya propiedad venia atribuida a María del Carmen Pazos, hija de José Manuel Pazos Nores que con su esposa y un tercero componían la sociedad dicha, que explotaba el buque, embarcación que, en 6 de Octubre de 1987, sufrió un incendio, aún vigente el seguro concertado, y poco después del siniestro, el 15 del indicado mes, la propietaria del buque, juntamente con su padre y el tercer socio de "Pandomar", y Francisco Mallo Area, con quienes, sin embargo, venía ya en negociación sobre la venta, de suerte que la utilizaban también los compradores, pero sin estar todavía consumada la venta, subordinada al total pago del precio, y para el cobro de lo adeudado por los desperfectos del buque, las dos empresas que las repararon demandaron a 


\begin{abstract}
"Pandomar" y Francisco Mallo -éste había firmado con "Pandomar S.A." las facturas de reparación, siendo "Pandomar S.A." la que reclama en el actual procedimiento la cantidad correspondiente a la reparación", resulta de toda evidencia que no cabe negar a "Pandomar, S.A." la existencia de un interés asegurable, ni de un interés económico, siendo irrelevante al respecto que en la escritura de constitución de la repetida sociedad apreciase que su objetivo social fuese el de importación y comercialización de pescado y productos del mar, así como cualquier actividad relacionada con lo anterior, y esto así, basta atender a las ineludibles consecuencias que derivan de los hechos probados, para comprender le imposibilidad de atribuir al Tribunal "a quo" la infracciones denunciadas en el primer motivo de recurso. (STS 31 diciembre 1996. En Gallego Sánchez, 2003, p. 1576)
\end{abstract}

3.1.3 Fisuras que se profundizan. No obstante las imprecisiones reseñadas y alguna posición aislada, parece existir consenso en la doctrina y la jurisprudencia acerca de la existencia concurrente del interés asegurable en los seguros reales, no solo en cabeza del propietario de los bienes (mercaderías para el tema tratado), sino también en cualquier persona que directa o indirectamente ostente una relación económica con estos. Lo que permite, en principio, concluir que, aun sin que se le haya transferido la propiedad de la mercancía, el comprador tendrá interés asegurable en el seguro real sobre las mismas (aunque se configure como uno de transporte), siempre que se le hayan entregado como una forma de transmitirle el riesgo, o que de alguna otra forma convencional se le haya radicado dicha carga -la del riesgo por la pérdida fortuita-. Igual sucederá con el vendedor, quien tendrá interés asegurable aun incluso después de la tradición (transferencia del dominio) de las mercancías, siempre y cuando no haya transmitido el riesgo a través de la entrega o de cualquier otra forma convencional; todo esto sobre la base del carácter esencialmente dispositivo de la Convención y de los INCOTERMS.

Las dudas se empiezan a profundizar, cuando no es claro el punto específico donde se transmite el riesgo que, como vimos, en el detallado proceso de distribución física internacional (DFI), puede coincidir o no con la entrega o con la tradición. Además, no se puede perder de vista la importancia económica que para una empresa pueden significar las operaciones de comercio internacional, representativas, en la mayoría de los casos, de cifras importantes que realmente justifiquen la puesta en marcha de un proceso logístico, en no pocas ocasiones, complejo. Por ello, es de vital importancia para las empresas exportadoras e importadoras tener un mecanismo ágil y eficaz que garantice un pago oportuno o un reembolso o restitución del precio anticipado en caso de resolución o extinción del contrato. Es tan importante que se tenga o no el derecho, como que este sea oportunamente satisfecho. 
No hace parte del objeto social de ninguna empresa exportadora o importadora de bienes el litigio o pelea judicial con sus clientes, en torno a la carga sobre el riesgo por la pérdida de las mercancías -fortuita o no-. Es este el fin último del seguro, tal como lo plantean Hours y Baus (1944) citados por Guzmán Escobar (2009, p. 167):

Para conseguir esta finalidad, el seguro tiende su manto protector, imponiendo al comerciante solo el pequeño sacrificio material de una módica prima, a cambio de romper la tradición llena de perjuicios reñidos con la razón pura, de batallar, no solo con la fatalidad y los elementos naturales desbordados o enfurecidos (casos fortuitos y de fuerza mayor), que rigen leyes supremas e inmutables, sí que también de quedar automáticamente prisionero en la tupida red de disposiciones legislativas que rigen en materia de responsabilidades a cargo de los porteadores que requieren una preparación técnica y un cuidado especial para que su derecho no se enerve. (...) En este orden de ideas, el seguro brinda al comercio seguridad absoluta de obtener siempre cumplida e inmediata reparación de eventuales daños que sufran sus expediciones, sin haber de preocuparse de contender con organismos prepotentes y monopolizadores, que por instinto de conservación, cuando no por natural egoísmo mercantil, han de adoptar una posición más o menos firme o legitima para la defensa de los intereses que tiene a su cuidado y responsabilidad.

Al exportador (vendedor), por ejemplo, le interesa que la mercancía llegue a su destino conforme con el contrato celebrado, independientemente de que haya transmitido el riesgo en un lugar anterior (como el puerto de origen); y, en caso de no llegar, por cualquier motivo, obtener el pago del precio de manera directa y sin importar si la pérdida obedeció a una culpa del comprador, o a una fuerza mayor o caso fortuito, o incluso a una culpa suya (en caso de que esté legítimamente asegurada); esta es la teleología propia del seguro real sobre las mercancías. El exportador no contrata el seguro para tener la certeza de que no fue él quien corrió con el riesgo, lo hace, se reitera, para obtener un pago oportuno, que le evite correr riesgos de liquidez que impidan su normal desarrollo. Será entonces la compañía de seguros la que determine si, una vez pagada la indemnización, reclama del responsable -vía subrogación- el rembolso por la suma pagada. De nada le sirve al vendedor saber que el riesgo por la pérdida de la mercancía corría por cuenta del comprador o que esta se perdió por su culpa (del comprador) si lo que realmente le interesa, que es obtener un pronto pago, no se obtiene oportunamente. Igual ejemplo le cabe al comprador (importador) que realiza un pago anticipado de la mercancía antes del despacho (o incluso antes del proceso de producción, como es común en el comercio de bienes).

Por la persistencia del interés asegurable Ossa (1991, p. 512) afirma: 
(...) aunque jurídicamente los riesgos se trasladan al comprador por ministerio de la ley (desde el momento de la entrega material), económicamente continúan gravitando sobre el patrimonio del vendedor en la medida de la parte insoluta del precio de la obligación. Y que, por tanto, subsiste en su cabeza un interés asegurable. Supuesta la insolvencia del comprador en caso de siniestro, o su renuencia al pago, el patrimonio del vendedor puede resultar afectado, directa o indirectamente por la realización de un riesgo, como reza textualmente el art. 1083 del código de comercio. El interés asegurable es un concepto económico y, como tal, es objeto del seguro.

El concepto de riesgo asegurable importa también y tiene que ver al concepto de interés asegurable en tanto la ocurrencia del riesgo puede responder a la pregunta sobre la existencia de interés asegurable, es decir, si la mercancía se pierde ¿se pierde para quién? Lo que lleva a una conclusión mayor, tiene un interés asegurable el comprador en la mercancía no solo como acreedor, de esta, como propietario, o como cargador del riesgo sobre ella, sino como posible afectado en su pérdida; es decir, aunque la cosa perezca para el vendedor, los riesgos patrimoniales que implicará el proceso de disputa entre uno y otro, son los que el comprador quiere evitar con la contratación del seguro, en la medida en que, se insiste, será la aseguradora, una vez pague el valor asegurado, quien se subrogue en los derechos del comprador como parte, e inicie las acciones pertinentes en torno a la responsabilidad del vendedor sobre el valor de los bienes vendidos, bien sea como real ostentador del riesgo, bien sea como responsable de la indemnización a título de culpa. Sería lógico pensar entonces en que el interés asegurable, en el caso de la compraventa internacional de mercaderías, equivale al derecho que tiene el comprador de recibir las mercancías o el reembolso del anticipo, y no las mercancías mismas. Será entonces más un seguro patrimonial que real.

Es hacia allí a donde deben apuntar las soluciones en el ámbito del comercio internacional y es por ello que debería eliminarse cualquier tipo de duda interpretativa que con respecto al interés asegurable en cabeza del vendedor, del trasportador o del comprador se pueda generar.

Como se vio, ni siquiera en los extremos de los términos comerciales INCOTERMS (EXW o DDP) es posible evitar puntos ciegos en cuanto a la entrega o a la transmisión del riesgo sobre las mercancías; o es posible que la pérdida no sea fortuita, y que en vez, obedezca a la culpa de alguna de las partes. Más aun, habrán casos en los que no se sabrá en que momento, con relación a la transmisión del riesgo, se presentó la pérdida de la mercancía, como sucede con las ventas en tránsito sobre documentos. Frente a estos tópicos que implican transmisión o mutación del riesgo se observan varias soluciones doctrinales y jurisprudenciales que pasamos a decantar a manera de conclusión. 


\title{
LA VENTA EN TRÁNSITO
}

Es una práctica reiterada en el comercio internacional, especialmente el que utiliza el transporte marítimo como medio, y muy especialmente el comercio de víveres y otros denominados commodities, el que se produzcan ventas en cadena o sucesivas mientras estos se encuentran en tránsito. Establece el artículo 68 de la Convención de Viena sobre compraventa internacional de mercaderías:

\begin{abstract}
ARTÍCULO 68: El riesgo respecto de las mercaderías vendidas en tránsito se transmitirá al comprador desde el momento de la celebración del contrato. No obstante, si así resultare de las circunstancias, el riesgo será asumido por el comprador desde el momento en que las mercaderías se hayan puesto en poder del porteador que haya expedido los documentos acreditativos del transporte. Sin embargo, si en el momento de la celebración del contrato de compraventa el vendedor tuviera o debiera haber tenido conocimiento de que las mercaderías habían sufrido pérdida o deterioro y no lo hubiera revelado al comprador, el riesgo de la pérdida o deterioro será de cuenta del vendedor.
\end{abstract}

Cuestión cardinal radica en determinar en qué consiste la frese "si así resultare de las circunstancias" que trae el artículo para radicar el riesgo en cabeza del comprador, no desde la celebración del contrato, sino desde que se pusieron las mercaderías en poder del porteador, pues dichas circunstancias pueden obedecer o bien a las prácticas y/o usos de las partes, o a los usos del comercio o la disposición expresa convencional de estas. En todo caso, lo que se plantea es que el comprador asuma una carga de manera retroactiva, encontrándose dentro de las posibilidades obvias, el que el riesgo se haya ya producido.

Acerca de las particularidades propias de esta norma en la Convención, Nicholas (2006) aclara que el artículo 68 es una disposición especial para las mercancías vendidas en tránsito (es decir, mientras que está en las manos de un operador transportador). En suma, una transmisión retroactiva de los riesgos del vendedor al comprador. Los argumentos a favor de la regulación, tal como fue aprobada, se centraron en que la misma representaba la práctica habitual en el comercio internacional, que el asunto era esencialmente una de las técnicas comerciales y de seguros, que las partes están más preocupados por la venta de los documentos que por la venta del propio producto y que si el riesgo tuviera que pasar desde el momento en que el contrato de compraventa fue realizado o perfeccionado (es decir, cuando las mercancías estaban en tránsito), sería necesario establecer con exactitud cuándo se produjo el daño y esto a menudo sería difícil o imposible. Sin embargo, al proyecto se oponían con vehemencia, en particular los representantes de los países en desarrollo, sobre la base de que era 
irracional e injusto poner el riesgo al comprador antes de que él hubiese contratado, e igualmente se sugirió también que el comprador no podía tener un interés asegurable hasta ese momento ${ }^{17}$.

El mismo autor citado por Bianca y Bonell (PACE) refiere que los motivos de las críticas se fundaban en que era irracional e injusto poner el riesgo en el comprador antes de que el contrato hubiese sido perfeccionado, y también en que el comprador no podía tener un interés asegurable hasta ese momento. Por otro lado, se argumentó a favor de la norma que esta representa la práctica habitual en el comercio internacional, que el asunto era esencialmente una de las técnicas comerciales y de seguros y que cualquier riesgo adicional a cargo del comprador se vería reflejado en el precio ${ }^{18}$.

La primera frase del mismo artículo establece la norma primaria de que el comprador asume el riesgo desde el momento en que se haya celebrado el contrato (es decir, mientras que los bienes están en tránsito). Cuando el daño con claridad es el resultado de un evento que permite ser identificado como una tormenta o una colisión, puede que no haya dificultades en la aplicación de la regla, pero es posible que no pueda identificarse un evento en particular como la causa (o la causa exclusiva) del daño.

Por otra parte, si el daño es atribuible en parte a un evento ocurrido después de la realización del contrato y, en parte, a un evento ocurrido antes de esa fecha, tanto el

17 En el mismo sentido de este, Bollée (2001): “At the Vienna Conference, the drafting of this provision unexpectedly gave rise to much controversy. The working group's draft reproduced the substance of Article 99 ULIS, according to which the risk was assumed retroactively by the buyer from the time the goods were handed over to the carrier. Such rule has practical advantages since it prevents splitting of transit risk. [86] Nevertheless, some delegates of developing countries objected that it was unfair to put the risk on the buyer before the time of the conclusion of the contract. It was added that the buyer could not have any insurable interest until he contracted to buy the goods. The supporters of this proposal replied that the buyer was not put in an uncomfortable position since the goods should be covered by insurance assigned to the buyer. The objectors retorted that the rule led to mandatory insurance of the goods, which resulted in a further transfer of resources from Third World to developed countries, [87] since the world insurance market was generally controlled by the latter. Such result was also unfair to buyers in developing countries, who would often prefer not to insure the goods but rather to bear the risk themselves. [88]". En relación con el origen de esta disposición, el propio Nicholas señala: "Esta disposición, que trata de la situación en la que los productos ya se encuentran en tránsito en el momento del contrato de venta, fue objeto de mucha controversia, tanto en la Comisión y la Conferencia de Viena (véase el Anuario, VIII, 1977), de 63 años; Documentos Oficiales, II, 213-215; 403-406). El proyecto de los Grupos de Trabajo se reproduce el contenido del artículo 99 de LUCI, por el que el riesgo debe pasar con efecto retroactivo desde el momento en que los bienes fueron entregados a la compañía (es decir, la disposición del texto, se aplica solo «si las circunstancias así lo indican»). Este proyecto fue aceptado, con un poco de disidencia, por la Comisión, pero se opuso a la Conferencia de Viena, tanto en la Primera Comisión y las sesiones plenarias".

18 Nicholas (2006): "El artículo contempla la situación en la que las mercancías se venden, mientras que ya se encuentra en tránsito y se encuentran deterioradas a su llegada al destino. La regla ordinaria en el artículo 67 (1) no puede aplicarse, ya que cuando los bienes hayan sido entregados al transportista, no se les entrega "como transmisión de propiedad al comprador". 
comprador como el vendedor tendrán que presentar reclamaciones derivadas de los acontecimientos (Nicholas, 2006).

La segunda frase, que se aplica "cuando las circunstancias así lo aconsejan", prevé que el riesgo deba pasar con carácter retroactivo desde el momento en que las mercancías sean entregadas al transportista. Esto evita las dificultades de la prueba y tiene la ventaja de que sólo el comprador debe presentar reclamaciones derivadas de los daños que se produzcan mientras que los bienes están en tránsito. Por otro lado, pone sobre el comprador las consecuencias de la falta de adecuación legal del seguro. La principal dificultad radica en el significado de "si las circunstancias asílo aconsejan", por lo que se debatió así la necesidad de inclusión en el contrato de compraventa de la obligación expresa del vendedor de transferir el contrato de seguro, frente a lo cual se argumentó que es una de las obligaciones comúnmente pactadas en dichos contratos (Nicholas, 2006).

Una mayor incertidumbre se deriva del uso de la palabra «las circunstancias», en lugar de una referencia a la intención de las partes. Esto podría entenderse como que la regla de esta segunda frase prevalecería sobre la intención de las partes, sin embargo la explicación más probable es que la palabra "circunstancias» se destina a cubrir la situación en la que la intención de las partes no se expresa, sino que debe inferirse de las circunstancias del contrato (Nicholas, 2006).

Una tercera cuestión que se plantea, es la referente al conocimiento que tenía o deberá tener el vendedor de la pérdida o deterioro de la mercancía y la imposibilidad de trasladar los riesgos al comprador en caso positivo y no mediando el aviso a este, sin embargo, la inquietud fundamental que se debe plantear en este supuesto es el caso contrario, es decir, que pasa si se da el aviso de siniestro o sospecha del mismo. ¿Podrá hablarse de riesgo asegurable en el seguro que tome el comprador?, ¿Habrá interés asegurable del comprador en unas mercancías que ya no existen o simplemente se puede hablar de riesgo putativo?, un riesgo putativo que en la navegación marítima colombiana es asegurable a la luz del artículo 1706 del Código de Comercio aplicables por remisión al trasporte aéreo, pero expresamente excluidas del transporte terrestre (art. 1054), algo de lo que la Convención obviamente no se ocupa, especialmente en relación a la validez del contrato de compraventa mismo o del contrato de seguro.

Ossa (1991, p. 54) en cuanto al riesgo putativo expresa que "en los seguros terrestres no constituye riesgo, ni pueden ser, por lo tanto, objeto de contrato, "la incertidumbre subjetiva respecto de determinado hecho que haya tenido o no cumplimiento" (art. 
1054), al paso que en los seguros marítimos es válido, el seguro sobre "riesgo putativo" a saber, "el que solo existe en la consciencia del tomador o del asegurado y del asegurador, bien sea por que ya haya ocurrido el siniestro o bien porque ya se haya registrado el feliz arribo de la nave al momento de celebrarse el contrato" (art. 1706).

Muy de presente debe tenerse además que el documento al que se refiere en las ventas cuyos objetos son transportados vía marítima es el conocimiento de embarque, documento que en Colombia y en la gran mayoría de regímenes es tratado como título valor representativo de mercaderías (art. 767) ${ }^{19}$. De allí que el artículo 923 consagre unas formas especiales de entrega pudiéndose aplicar en defecto de ellas, las generales del código civil, conforme lo expresado en el numeral $1^{\circ}$ de dicha norma. Oviedo Albán (2008, p. 524): “ARTÍCULO 923: la entrega de la cosa se entenderá verificada: Por la transmisión del conocimiento de embarque, carta de porte, o factura, durante el trasporte de las mercadería por tierra, mar o aire; (...)”.

De manera que si la entrega se hace a partir de este tipo preciso de documentos, el comprador se hará dueño y no pareciera haber problemas con relación a su interés asegurable -desde este momento-; pero las dificultades siguen persistiendo, si se observa que el artículo 770 del Código de Comercio prescribe que "El endosante responderá de la existencia de las mercancías en el momento del endoso"; y que los INCOTERMS 2010 establecen como una forma de entrega para las ventas en tránsito el que el vendedor "procure" las mercancías, queriendo significar con ello, que garantice que se han entregado en la forma en que se establece en cada término ${ }^{20}$. Así, entonces, ¿quién tendrá interés asegurable en este tipo de ventas?, ¿qué sucede si la mercancía pereció antes de darse el endoso?, ¿quién está legitimado para hacer la reclamación al asegurador? Aunque con un menor grado de complejidad, estos mismos interrogantes se presentan en cualquier clase de venta (nacional o internacional).

19 Al respecto remitirse a las precisiones realizadas en relación con la carta de porte y guía área en el transporte aéreo.

20 INCOTERMS 2010 CCI (2011, p. 12): "En las ventas de productos básicos, a diferencia de las ventas de mercancías manufacturadas, es frecuente que la carga se venda varias veces en ruta, "en cadena". Cuando esto ocurre, el vendedor que se halla en medio de la cadena no "embarca" la mercancía porque ya ha sido embarcada por el primer vendedor de la cadena. El vendedor del medio de la cadena cumple por lo tanto con sus obligaciones respecto a su comprador no embarcando la mercancía, sino "proporcionando" la mercancía que ha sido embarcada. Con propósitos aclaratorios, las reglas Incoterms 2010 incluyen la obligación de "proporcionar la mercancía embarcada" como alternativa a la obligación de embarcar la mercancía en las reglas Incoterms pertinentes". 
